\title{
COVID-19 y el paciente en el consultorio odontológico
}

\author{
COVID-19 and the patient in the dental clinic
}

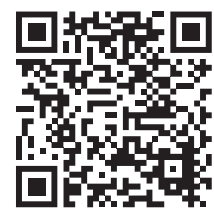

Enrique Ensaldo Carrasco*

\section{RESUMEN}

En el área odontológica, además de considerar las vías de contagio viables como la respiración de aerosoles de pacientes contagiados de COVID-19, contacto de objetos y superficies contaminadas con el virus, es importante considerar el contacto con la saliva, que es inevitable en un consultorio dental. La infección por SARS-CoV-2 representa para los odontólogos un riesgo profesional inherente en el consultorio, por los aerosoles y salpicaduras provenientes de la interacción del equipo dental y la saliva del paciente. Existen tres principales medidas preventivas que son aplicables al paciente y al personal que trabaja en una clínica o consultorio dental, además del equipo de protección personal y ocular y ropa de trabajo, la limpieza y la desinfección del consultorio también son barreras de protección.

Palabras clave: COVID-19, consultorio odontológico, equipo de protección, limpieza.

\begin{abstract}
In the dental area, in addition to considering viable contagion routes such as the breathing of aerosols from patients infected with COVID-19, contact with objects and surfaces contaminated with the virus, it is important to consider contact with saliva, which is unavoidable in an office dental. The SARS-CoV-2 infection represents an inherent professional risk for dentists in the office, due to aerosols and splashes from the interaction of dental equipment and the patient's saliva. There are three main preventive measures that are applicable to the patient and staff working in a dental clinic or office, in addition to personal and eye protection equipment and work clothes, office cleaning and disinfection are also protective barriers.
\end{abstract}

Keywords: COVID-19, dental office, protective equipment, cleaning.
* Estomatólogo especialista en Endoperiodontología. Profesor-Investigador adscrito a la Universidad Autónoma Metropolitana.

Correspondencia: EEC, enriqueensaldo@ msn.com

Conflicto de intereses: Sin conflicto de intereses. Citar como: Ensaldo CE. COVID-19 y el paciente en el consultorio odontológico. Rev CONAMED. 2020; 25(supl. 1): s41-s47. https://dx.doi. org/10.35366/97347 Financiamiento: No hubo financiamiento.

Recibido: 13/11/2020.

Aceptado: 13/11/2020

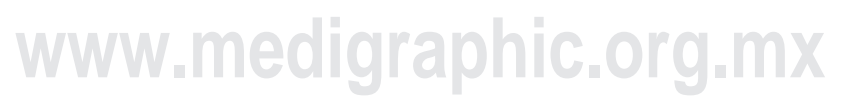


La COVID-19 es una enfermedad nueva que se originó en Wuhan, China en diciembre de 2019, la mayoría de los casos presentan síntomas menores y en algunos casos puede complicarse con un síndrome respiratorio agudo, que puede poner en peligro la vida de los pacientes. Entre los signosy síntomas más comunes tenemos fiebre, fatiga, dolor muscular, náuseas, vómito, diarrea, dolor de cabeza, congestión nasal, pérdida del olfato, pérdida del gusto, dolor de garganta y dificultad para respirar.

\section{VÍAS DE CONTAGIO}

Las vías de contagio que hoy en día son consideradas como viables para que se produzca un contagio son:

- El contacto con personas infectadas.

- La respiración de gotículas provenientes de nariz y boca.

- Por aire, ya sea por aerosoles o por aumento de la carga viral en espacios cerrados.

- El contacto con objetos y superficies contaminadas que pueden llevar al virus a las manos, y producir la autoinoculación cuando el individuo se toque la cara (ojos, boca, nariz).

El contacto con objetos contaminados es considerado de bajo riesgo, aunque es importante resaltar que en Odontología realmente no hace mucha diferencia, ya que debemos considerar todas las vías como de alto riesgo. La propagación por aire ha tenido todos los reflectores últimamente, porque al principio de la pandemia sólo se veía como una posibilidad, en la actualidad es considerada como vía de contagio; sin embargo, para que exista tienen que presentarse algunas situaciones, como lo son: una habitación cerrada o con poca ventilación donde estén una o varias personas infectadas, que al exhalar estén Ilenando el cuarto con SARS-CoV-2, entre más tiempo el aire se quede estancado en el cuarto, será cada vez más factible que exista el riesgo de que personas sanas pudieran contagiarse al respirar el aire de esa habitación sin ventilación o mal ventilada.

\section{PREVENCIÓN}

Etiqueta respiratoria (evitar toser y/o estornudar en las palmas o dorso de las manos y utilizar la parte interna del antebrazo o el ángulo del codo).

Lavado de manos, que para la población en general se recomienda que mínimo dure 20 segundos, para los profesionales de la salud en situaciones de trabajo la Organización Mundial de la Salud (OMS) recomienda que sea de 40 a 60 segundos. El uso de cubrebocas y mantener una distancia mínima de metro y medio entre personas (sana distancia).

Para dar un poquito más de contexto de cómo se está desarrollando la Odontología en la pandemia es que voy a citar una serie de extractos de artículos:

Carta del editor: «La combinación de la carencia de una vacuna y ninguna contra medida terapéutica efectiva al 100\% nos presenta ante un escenario desconocido pero desafiante con millones de personas infectadas a nivel mundial».

"Una vez en el cuerpo humano el SARS-CoV-2 estará presente abundantemente en secreciones nasofaríngeas y salivales de los pacientes infectados».

"La saliva puede albergar varios tipos de virus incluidos el SARS-COV-2, la posibilidad de transmisión a través de la saliva es inevitable en un consultorio dental».

«EI SARS-CoV-2 puede permanecer viable hasta nueve dias en superficies contaminadas y hasta nueve horas en piel humana», existen varias publicaciones que nos indican cuánto tiempo puede sobrevivir el virus en diferentes superficies, pero decidíno usar esta referencia, porque quería resaltar el hecho de que las superficies pueden quedar contaminadas por un largo periodo de tiempo sin que realmente importe el tipo de material de superficie, porque al final lo único que debemos entender es, que las superficies de los consultorios pueden estar contaminadas por varios días, incluyendo nuestra piel y la del personal del consultorio, lo cual termina reforzando todas las medidas de protección que vamos a revisar más adelante.

"Los tratamientos dentales involucran interacción cara a cara con los pacientes, así como la exposición frecuente de saliva, sangre y otros fluidos». 


\section{RECOMENDACIONES PARA PREVENIR EL CONTAGIO POR SARS-COV-2 EN EL CONSULTORIO DENTAL}

Es importante recalcar que las recomendaciones que veremos a lo largo de esta presentación están siendo constantemente actualizadas, por lo cual la fecha está resaltada (20 de octubre del 2020) porque lo más probable es que si esta presentación la revisamos en seis meses o un año, muchas de las recomendaciones habrán cambiado, no serán tan estrictas, o al contrario y cada vez sean más estrictas. Por lo que debemos estar en constante actualización, y aunque todavía falta mucha información, es importante recalcar que por lo menos en México no contamos con datos del índice de contagio en Odontólogos por COVID-19 o de cuántos han muerto, sería de mucha ayuda si a lo largo de esta plática pudieran compartir en los comentarios su experiencia, si saben de compañeros odontólogos contagiados o inclusive que hayan muerto, o si ustedes mismos se llegaron a enfermar.

La infección por SARS-CoV-2 representa para las y los Odontólogos un riesgo profesional inherente en el consultorio, ya que se producen continuamente aerosoles y salpicaduras provenientes de la interacción de equipo dental y la saliva del paciente. La información con la que contamos en este momento sólo refuerza la idea de que como odontólogos estamos muy expuestos.

Para facilitar la asimilación de la información, las recomendaciones para recibir al paciente en la atención clínica han sido divididas en cuatro:

1. Antes de acudir a la consulta.

2. En área de recepción.

3. En sala de espera.

4. Otras áreas clínicas.

La manera más eficiente de erradicar los contagios en el consultorio es evitando que el virus llegue a consulta, esto es obvio, si no tenemos virus en la consulta el contagio será inexistente, pero eso se traduce en no atender a ningún paciente; sin embargo, hay mecanismos que nos pueden ayudar a evitar que el virus entre a nuestros consultorios, como lo son el uso de triajes, que son los cuestionarios que tenemos que aplicar a los pacientes antes de la consulta, los cuales se pueden realizar un día antes de la cita o cuando el sujeto llegue al consultorio, en la página oficial de CONAMED, en el apartado de infografías pueden bajar los formatos e imprimirlos para anexarlos a sus expedientes.

\section{Las instrucciones telefónicas para al paciente son:}

Asistir a consulta preferentemente solo, en caso de procedimientos como cirugías, etcétera, podrá llevar a un acompañante o en el caso de que sea un menor de edad. No llevar objetos que pudieran contaminarse tan fácilmente como joyas, aretes, pulseras, collares, relojes y anillos. Asistir con cubrebocas bien colocado y de preferencia sin válvula de exhalación, estos cubrebocas no son recomendables, porque al exhalar el aire que sale por la válvula lo hace sin filtración, lo que pone en riesgo a los de alrededor. Quitarse el cubrebocas cuando se le indique. Mantener en la medida de lo posible la sana distancia, lo cual podría parecer absurdo, porque en la consulta dental no puede existir la distancia, pero nos referimos a la sana distancia que debe haber entre los pacientes y demás personal administrativo en las instalaciones del consultorio, como la recepción, sala de espera, área de sanitarios, pasillos o inclusive en elevadores y escaleras.

Para el pago de honorarios de preferencia con el uso de tarjetas bancarias en lugar de efectivo, para evitar contaminación cruzada.

\section{Al entrar al consultorio hay tres medidas que son aplicables tanto para casos como para todo el personal que trabaja en el consultorio o clínica}

1. Para la desinfección de calzado se puede utilizar un tapete sanitizante o botas quirúrgicas.

2. Toma de temperatura para el paciente y el personal que labora en la clínica o consultorio, cualquier persona que tenga una temperatura de 37.5 o más no podrá ingresar al consultorio.

3. Desinfección de manos para todos los que ingresen al consultorio, puede ser con un lavado de manos de al menos 20 segundos o con alcohol en gel al 70\%.

4. Solicitar que permanezca sentado en la sala de espera hasta ser llamado. (Esta última sólo aplicable a los pacientes). 
En el área de recepción, instalar mamparas para proteger a la persona que está a cargo de la recepción, la cual también deberá usar lentes de protección, cubrebocas sin válvula, (mascarilla quirúrgica), señalizar la sana distancia en el piso para que el paciente sepa cuál es la distancia que deberá mantener, si la persona de recepción recibe algún pago (con tarjeta de crédito o efectivo) puede utilizar guantes, los cuales tendrá que desechar cada vez que reciba un pago o maneje alguna superficie posiblemente contaminada, también podría no usar guantes y limpiarse las manos (alcohol 70\% o agua con jabón) siempre que termine de cobrar, desinfectarían la terminal y se puede optar por desinfectar el efectivo para reducir aún más el riesgo de infecciones cruzadas.

Las recomendaciones para la sala de espera van encaminadas a reducir el número de personas en el consultorio, además de disminuir la cantidad de superficies que pudieran contaminarse, por lo que se recomienda agendar a los pacientes con suficiente espacio entre citas para evitar aglomeraciones en la sala de espera, y como máximo tener un solo paciente esperando, dejar un mínimo de sillas (si se puede) o al menos marcar las que sí se pueden utilizar, tomando en cuenta la sana distancia (que en México es de un metro y medio), la cual tendremos que señalizar para todos los sitios donde los pacientes pudieran encontrarse, retirar revistas, juguetes, cuadros y diplomas así como muebles y adornos innecesarios e indicar al paciente que no se retire el cubrebocas hasta que se le indique. Tener alertas visuales además de las que ya tenemos (rutas de evacuación, extintor etcétera) que proporcionen al paciente información sobre COVID-19, prevención, uso de cubrebocas, técnica de lavado de manos, sitios donde el paciente pudiera encontrar alcohol en gel, etcétera.

También hay que optar por toallas desechables y dispensadores de jabón líquido. Para la ventilación es un poquito más complicado dar una recomendación ya que existen muchas publicaciones que apoyan el no utilizar ningún tipo de ventilador y/o aire acondicionado, pero se entiende que hay situaciones donde el uso de aire acondicionado es una necesidad, como en otras partes de la república por ejemplo, pero hay que tener mucho cuidado con ventiladoresy aires acondicionados, en especial con los que reciclan el aire. Lo que debemos entender es si se recicla aire con carga viral proveniente de los aerosoles y la misma respiración y no hay recambio de ese aire, puede aumentar la posibilidad de un contagio por vía aérea. Si se van a utilizar ventiladores y/o aire acondicionado utilizar algún tipo de purificador o filtros HEPA, o al menos abrir ventanas para permitir el recambio de aire y evitar su reciclado.

\section{EQUIPO DE PROTECCIÓN PERSONAL (EPP)}

Todo el personal involucrado en el tratamiento del paciente (odontólogos, asistentes, circulantes, instrumentistas etcétera) deben usar EPP.

El cubrebocas o mascarilla quirúrgica (que es la que hemos utilizado desde hace mucho tiempo), funciona para la mayoría de los tratamientos (siempre y cuando no se produzcan aerosoles) como en situaciones de diagnóstico o toma de radiografías, etcétera. Si utilizamos una pieza de alta o algún instrumento que pudiera ocasionar aerosoles, tendremos que utilizar los respiradores N95, los cuales son el estándar de oro para estos procedimientos. Evitar los cubrebocas con válvulas de exhalación, para evitar contagiar a los pacientes y demás personal del consultorio. Si sólo tienen cubrebocas con válvula de exhalación, deberán utilizarse con una mascarilla quirúrgica sobre la válvula. En México, la Asociación Dental Mexicana (ADM) recomendó no reutilizar los cubrebocas, pero si existiera la necesidad de reutilizar cubrebocas existen guías que nos pueden decir cómo podemos reutilizarlos y en qué momento, pero no existe una repuesta exacta sobre cuánto tiempo podemos reutilizar un cubrebocas. Lo que sí queda muy claro es la necesidad de revisar la integridad física del cubrebocas, calidad del sellado alrededor de la boca-nariz y posibles cambios de color. Tenemos que evitar que los cubrebocas se mojen, si esto llegara a pasar tendríamos que cambiarlo inmediatamente ya que disminuye drásticamente la capacidad del filtrado.

Para la utilización de guantes no hay ningún cambio, pero algunas guías recomiendan utilizar doble par, para tener un par limpio por debajo del que usamos en la atención odontología que usaremos para quitar nuestro EPP. Para actividades de limpieza utilizar guantes gruesos, que se pueden conseguir en cualquier supermercado. 


\section{PROTECCIÓN OCULAR}

La protección de ojos en situaciones donde fácilmente podrían contaminarse y/o dañarse con químicos, virus, bacterias etcétera es indispensable en la consulta odontológica. Se recomienda utilizar lentes de protección o caretas, estas últimas ofreciendo mayor protección ya que evita que los cubrebocas se pudieran humedecer.

\section{RECOMENDACIONES PARA LA ROPA DE TRABAJO}

Evitar llegar al consultorio con el uniforme puesto, tampoco atender con ropa de calle.

El uniforme puede ser una «pijama quirúrgica» y bata, para atender pacientes se deberá usar además el EPP (gorro quirúrgico, bota quirúrgica y sobrebata o algún overol) además de contar con calzado únicamente de uso en el consultorio (que sea libre de agujetas y liso). Al terminar nuestra jornada de trabajo no debemos salir con el uniforme y el calzado, aunque se hayan utilizado EPP, por lo que tendremos que cambiarnos nuevamente. El uso de sobrebatas y overoles, es importante, por lo que se pueden utilizar cualquiera de las dos, siempre y cuando sepamos cómo ponerlo y cómo quitarlo, además de los extras que podríamos necesitar, como el uso de otra sobrebata con el overol para proteger el la zona del cierre, la cual podría servir como retención mecánica para bacterias, virus, etcétera.

En Odontología estamos más familiarizados con las sobrebatas porque la hemos utilizado desde hace mucho tiempo, incluso los programas de estudios de varias licenciaturas las usan. Puede ser de tela o desechable, pero ambas impermeables, deben cubrir la zona del cuello y tener puños. Las sobrebatas tienen la ventaja de ser lisas por la parte de enfrente y que se pueden quitar de atrás hacia adelante, disminuyendo el riesgo de contaminación cruzada. Los overoles, los cuales son nuevos en odontología, también funcionan, pero hay que tener en cuenta que tienen un cierre en la parte del frente, el cual tiene que cubrirse con un delantal o una sobrebata. Sin importar cuál decidan utilizar, deberán estar familiarizados con las técnicas para el uso apropiado. La Organización Mundial de la Salud (OMS) en su portal de internet tiene varias guías para el manejo de EPP.
Los Odontólogos que ya tienen tiempo trabajando en situación de pandemia saben lo estresante que puede ser el uso de todo el EPP, por lo que también es recomendable que usen aquél con el que se sientan más cómodos.

El Centro para el Control y Prevención de Enfermedades (CDC) tiene como estándar de oro para EPP el uso de sobrebata, careta o lentes de protección y un respirador N95, y como EPP aceptable lo mismo que el anterior pero sin respirador N95, el cual lo cambia por una mascarilla quirúrgica. En Odontología es necesario agregar gorro y botas quirúrgicas. Los EPP tienen tanta importancia que existe literatura que nos da recomendaciones para su uso y disminuir el riesgo de contaminación cruzada, la mayoría termina concluyendo lo que ya habíamos mencionado anteriormente, debemos de conocer las técnicas la utilización de los EPP, para evitar ponernos en una situación de contagio por autoinoculación del SARS-CoV-2, sin importar si utilizan sobrebatas u overoles.

\section{LA LIMPIEZA Y DESINFECCIÓN DEL CONSULTORIO}

Para cualquier actividad de limpieza, desinfección, remoción de barreras de protección de las unidades, traslado de material y/o instrumental el uso del EPP es obligatorio.

Después de atender a cualquier persona (sin importar si sólo se hicieron actividades de diagnóstico) se deberán cambiar las barreras de protección y limpiar la unidad, porque como sabemos el simple hecho de hablar o respirar es suficiente para que exista la contaminación de superficies.

Los productos que normalmente se utilizan para la limpieza y desinfección del consultorio son eficaces frente al coronavirus, existen varias opciones, pero las más simples y con acción probada sobre el SARS-CoV-2 son el uso de alcohol al 70\% e hipoclorito de sodio al 0.1\%. Pero no debemos olvidar que hay otros microorganismos patógenos que son más difíciles de eliminar.

Tenemos que ventilar el área clínica después de atender un paciente y con más razón si se hicieron actividades que hayan generado aerosoles, con un tiempo de cinco a 10 minutos de ventilación natural es suficiente, si fuera necesario utilizar algún tipo de ventilación artificial (como aire acondicionado 
o ventiladores, que sabemos no es lo ideal), se recomienda hacerlo con ventanas abiertas pero sin personal o pacientes hasta que se haya terminado de ventilar el área.

Todo el instrumental (incluyendo pieza alta y baja) será transportado al área de esterilización para su limpieza y esterilización.

Para los productos de limpieza y desinfección, debemos leer cuidadosamente las etiquetas, para tener toda la información del producto, incluyendo instrucciones de uso, composición, etcétera. Antes de desinfectar una superficie tenemos que lavarla, ya sea con agua y jabón o algún detergente, existen productos que ya incluyen un detergente y un desinfectante en su composición, pero aun así, primero tendrían que aplicarlo una vez para limpiar y otra para desinfectar. No olvidemos cronometrar el tiempo que debe mantenerse el desinfectante en contacto con las superficies (leer etiqueta) para que cumpla con su función y se logre la completa eliminación de patógenos. En la agencia de protección ambiental de Estados Unidos en su portal oficial, ustedes pueden entrar para buscar el desinfectante que quieran utilizar, y saber si elimina al virus SARS-CoV-2. La búsqueda se puede hacer por ingrediente activo, sitios de uso, por tiempo de contacto o incluso pueden buscar en toda la base de datos e imprimirla.

Pueden buscar el nombre del producto de su interés, y si está en la base de datos, les dará información como el número de registro, ingrediente activo, nombre de la compañía que lo produce, en qué tipo de microorganismos actúa, tiempo de contacto que se necesita para la desinfección total, si está lista para ser usada o hay que diluir y los sitios donde se puede utilizar (centros de salud, institucionales, en casa habitación, etcétera). Es importante recordar que aunque los amonios cuaternarios (que en México es mejor conocido como cloruro de benzalconio) son útiles para el SARSCoV-2, no lo son para otros tipos de patógenos más difíciles de destruir. Al revisar la composición de los productos de limpieza y desinfección podremos darnos cuenta de que normalmente en su formulación tienen químicos que aumentan la cantidad de patógenos que puede destruir. Hay que evitar el uso de desinfectantes en envases presurizados ya que no podemos estar completamente seguros de que la sustancia activa es la primera en entrar en contacto con la superficie que queremos desinfectar, y esto puede levantar el virus de la superficie y ponernos en una situación de contagio. La utilización de paños humedecidos con la sustancia de su preferencia es lo más recomendable, pero en caso de utilizar solución de hipoclorito de sodio al 0.1\% recordar que se tiene que preparar todos los días, ya que si la almacenan para usar en otro día, podría no funcionar. Para hacer la solución de hipoclorito de sodio al $0.1 \%$ sólo se necesita utilizar 25 mililitros de cloro al 5.25\% en un litro de agua destilada.

\section{EL TRATAMIENTO ODONTOLÓGICO EN LA PANDEMIA POR SARS-COV-2}

Existen varias recomendaciones a tomar en cuenta durante la consulta, la primera es que si tenemos varias unidades dentales, deberán estar separadas con mamparas para evitar contaminación cruzada y si se van a generar aerosoles, evitar atender a más pacientes al mismo tiempo durante el procedimiento. Nunca se deberá atender a ningún paciente sin la utilización de EEP. La literatura ha reportado que se pueden utilizar enjuagues bucales, para la eliminación o disminución de SARSCoV-2 de la saliva del paciente antes de atenderlo. Las soluciones más recomendadas en la literatura son el gluconato de clorhexidina, iodopovidona y el peróxido de hidrógeno al 1\%. Existe literatura que advierte que se necesita más información para saber si el uso de enjuagues preconsulta realmente funciona.

Se debe evitar en la medida de lo posible la producción de aerosoles, pero si fuera necesario, se puede utilizar dique de hule, el cual puede bloquear hasta el 70\% de las emisiones de aerosoles contaminados. Y aunque existen muchos procedimientos en los que siempre se ha utilizado (en tratamiento de conductos, operatoria, entre otros) la mejor recomendación sería utilizarlo en la mayor cantidad de procedimientos que se pueda. La utilización de eyectores de alta potencia también disminuye notablemente la salida de aerosoles. La manera más eficiente para evitar la formación de aerosoles en la consulta es utilizar instrumentación manual (cúretas, cucharillas, etcétera) y sólo utilizar las piezas de baja y alta en situaciones donde no exista otra opción, manteniendo el área ventilada (sin uso de ventiladores y/aire acondicionado). 
Nuestros pacientes también deberán utilizar EPP durante los procedimientos odontológicos. El sujeto deberá quitarse el cubrebocas al inicio del trabajo clínico, pero al término del tratamiento deberá colocárselo inmediatamente. Es normal que nuestros pacientes tengan dudas de los procedimientos que se realizaron, pero éstas deberán ser aclaradas con el cubrebocas puesto, para disminuir aún más la contaminación de superficies por gotículas.

El lavado de manos en odontología es de suma importancia, en el portal de la OMS, se puede acceder a guías para el lavado de manos. Hay que destacar que el lavado de manos debe durar entre 40 a 60 segundos, y se deberá realizar antes de tocar al paciente, antes de manipular instrumental y/o material, después de tener contacto con secreciones, cuando terminemos con el paciente y si tocamos alguna superficie que pudiera estar contaminada.

Al terminar de atender a un paciente todo el material deberá ser transportado al área del lavado y esterilización, recordar que la Norma Oficial Mexicana nos pide que usemos autoclaves para este propósito, porque la pieza de alta sólo puede ser esterilizada por este medio. Se deberán desinfectar caretas y lentes de protección de nuestros pacientes así como los de los operadores y/o asistentes. Todas las barreras de protección de la unidad y personales deberán tratarse como contaminadasy ser desechadas (si es que son desechables) y cambiarlas por unas limpias o nuevas antes de atender a otro paciente. Las piezas de mano deberán contar con válvulas antirretracción, de lo contrario se puede contaminar todas las líneas de agua de la unidad y favorecer la contaminación cruzada. Antes de desinfectar y esterilizar las piezas de mano es necesario purgarlas al menos durante un minuto, para después lubricar y esterilizar a 120 grados centígrados 15 libras de presión por 15 minutos (se recomienda revisar las indicaciones del fabricante).

Para las impresiones de alginato y elastómeros, los cuidados generales incluyen el enjuagar al chorro de agua para quitar la materia orgánica, se pueden desinfectar con una solución de hipoclorito de sodio al 0.1 o 1\% dejándolas sumergidas al menos 10 minutos, también existen productos específicos que pueden tener sales de amonio cuaternario y otros componentes como el etanol. Una vez terminados los 10 minutos, enjuagar con agua para después correr la impresión.

Al terminar la consulta del día, se procederá a limpiar las instalaciones del consultorio, evitando la dispersión del virus, por lo que se recomienda no utilizar escobas o aspiradoras en un inicio, de preferencia antes de utilizarlas limpiar las superficies con algún desinfectante usando una jerga o trapeador con el detergente de su preferencia y después barrer o aspirar. Lavar y desinfectar todas las superficies, manijas, puertas, enchufes, sillas, sillones del área de espera, equipos de cómputo, teléfonos y demás mobiliario de consultorio. Purgar las líneas de agua con hipoclorito de sodio al 0.1\%. Quitarse la ropa de trabajo y recordar que aunque se haya utilizado EPP, no se debe salir del consultorio con el uniforme y calzado de trabajo. Mucha de la información aquí presentada se encuentra en el portal oficial de CONAMED, donde puede acceder a varias infografías sobre COVID, EPP entre otras, la cuales pueden imprimir en tamaño carta o cartel.

Todavía existe mucha incertidumbre sobre las implicaciones del SARS-CoV-2 en la práctica odontológica; sin embargo, ante esta incertidumbre lo importante es hacer uso de la información que tenemos a nuestra disposición para protegernos, así como a nuestros pacientes, al personal del consultorio y a nuestras familias.

\section{Biblografía}

1. Praty C. COVID-19: it impact on dental schools: in Italy, clinical problems in endodontic theraphy and general considerations. Intern Endod Jour. 2020: 723

2. Ather A. Coronavirus disease 19 (COVID-19): implications for clinical dental care. J Endod. 2020; 46 (5): 584-595. doi: 10.1016/j.joen.2020.03.008.

3. Baghizadeh FM. Oral saliva and COVID-19. Oral Oncol. 2020: 104821. 